\title{
Inspiring future experimental scientists through questions related to colour
}

\author{
Mark Fairchild, Manuel Melgosa
}

Mark D. Fairchild, Manuel Melgosa, "Inspiring future experimental scientists through questions related to colour," Proc. SPIE 9289, 12th Education and Training in Optics and Photonics Conference, 928907 (17 July 2014); doi: $10.1117 / 12.2070279$

SPIE Event: 12th Education and Training in Optics and Photonics Conference, 2013, Porto, Portugal 


\title{
Inspiring future experimental scientists through questions related to colour \\ Manuel Melgosa*a ${ }^{* a}$ Mark D. Fairchild ${ }^{b}$ \\ ${ }^{a}$ Department of Optics, Faculty of Sciences, University of Granada, 18071 - Granada (Spain); \\ ${ }^{b}$ Munsell Colour Science Laboratory, Rochester Institute of Technology, Rochester NY (USA)
}

\begin{abstract}
In general, it can be stated that unfortunately in most countries the number of students interested in traditional scientific disciplines (e.g. physics, chemistry, biology, mathematics, etc.) for his/her future professional careers has considerably decreased during the past years. It is likely that among the reasons of this trend we can find that many students feel that these disciplines are particularly difficult, complex, abstract, and even boring, while they consider applied sciences (e.g. engineering) as much more attractive options to them. Here we aim to attract people of very different ages to traditional scientific disciplines, and promote scientific knowledge, using a set of colour questions related to everyday experiences. From our answers to these questions we hope that people can understand and learn science in a rigorous, relaxed and amusing way, and hopefully they will be inspired to continue exploring on their own. Examples of such colour questions can be found at the free website http://whyiscolor.org from Mark D. Fairchild. For a wider dissemination, most contents of this website have been recently translated into Spanish language by the authors, and published in the book entitled "La tienda de las curiosidades sobre el color" (Editorial University of Granada, Spain, ISBN: 9788433853820). Colour is certainly multidisciplinary, and while it can be said that it is mainly a perception, optics is a key discipline to understand colour stimuli and phenomena. The classical first approach in colour science as the result of the interaction of light, objects, and the human visual system will be also reviewed.
\end{abstract}

Keywords: Colour, Vision, Colour Science, Colour Education, Colour Image, Visual Perception, Visual Optics

\section{INTRODUCTION}

The future of science is in the hands of our school children and it is becoming increasingly difficult to encourage them to choose the "difficult" science majors when they move on to college. While it is general agreed that science is important to improve our quality of live, and solve relevant problems related to human health, economical development, environment protection, international security, etc., the interest in college education and ultimate careers in the basic sciences, engineering and mathematics remains depressed. ${ }^{1}$ An important percentage of adult and young people consider physics, chemistry, biology, or mathematics as intrinsically complex, abstract and even boring disciplines. Usually they feel much more interested and motivated by applied science, missing the key role of basic scientific knowledge.

In Spain, during the decade 2001-2011 the number of university students in scientific disciplines has decreased 29.1\%, beside the total number of students at university has increased. ${ }^{2}$ As an example, Figure 1 shows the percentage of students following traditional scientific disciplines in an old traditional university in Spain during the past 18 academic years. As we can see, the percentage of students in geology, mathematics, chemistry and physics decreased more than $50 \%$ in this period. Fortunately, it is also possible to note in Fig. 1 a slight increment in the number of students for some disciplines (particularly for chemical engineering) during the last 4 academic years.

As stated by the U.S.A National Science Foundation "Key challenges for undergraduate education in science and engineering include preparing teachers for K-12 and college levels, .., providing understanding of basic sciences and mathematics concepts for all students... The need for undergraduate teaching that could attract and retain students in science and engineering fields has been widely noted and discussed." This paper describes some efforts to stimulate scientific thinking in students of all ages, introduce them to science in a friendly, practical way, and perhaps inspire some of them to follow scientific careers. Colour, closely related to optics, is the specific topic we have chosen in our current proposal.

*Mecenas Building, First Floor, Office 107. E-mail: mmelgosa@ugr.es; phone +34958 246364; fax +34 958249533

12th Education and Training in Optics and Photonics Conference, edited by

Manuel F. P. C. Martins Costa, Mourad Zghal, Proc. of SPIE Vol. 9289, 928907

(c) 2014 SPIE, OSA, IEEE, ICO · doi: 10.1117/12.2070279

Proc. of SPIE Vol. $9289928907-1$ 


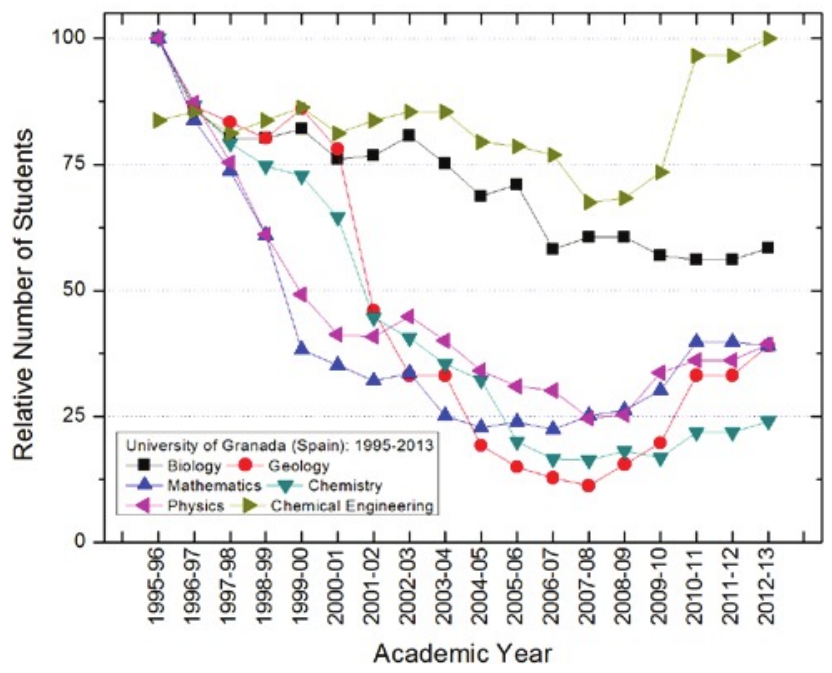

Figure 1. Change in the percentage of students for some scientific disciplines taught at the Faculty of Sciences of the University of Granada (Spain) during the past 18 academic years. Source: Secretary of the Faculty, http://fciencias.ugr.es/

\section{THE COLOR CURIOSITY SHOP}

The project entitled "The color curiosity shop" evokes the concept of wandering about a curious shop with no particular objective, but enjoying with a curious inquisition that which is found. The result of this project can be found at Fairchild's free website <whyiscolor.org $>$. Over the course of about one year, Fairchild received over 300 questions related to colour from teachers and students in different education levels, and provided appropriate answers to each question. This material was reviewed and ordered to select a final set of 56 questions, which corresponding answers are illustrated by appropriate photographs (most of them original). The website structure is a set of 64 modules arranged as 8 questions with increasing level in 7 different scientific disciplines (remember that colour science is multidisciplinary). It was preferred to use and accessible language for the names of such disciplines using words as light, objects, eyes, numbers etc. in place of the academic rigorous terms: optics, chemistry, biology, mathematics, etc. The materials are useful to people in a wide age range: From 3-4 years old (level 1) to undergraduate students (level 8), approximately. Specifically, the questions addressed in the different modules and levels are as follows:

\section{1. $L I G H T$}

1. What is color?

2. Why is a rainbow?

3. What is the best color for sunglasses?

4. Why is the sky blue?

5. How do fireworks make light and color?

6. How does the light affect how bright a color appears?

7. What is light?

8. Why can we only see visible radiation?

\section{OBJECTS}

1. Why are leaves green?

2. Why do colors of stained glass windows look so beautiful and different from other objects?

3. Why do leaves change in the autumn?

4. Would a dark colored M\&M melt faster than a light one?

5 . How does a mood ring work? What do the colors mean?

6 . Why is green often used for surgeons' scrubs? 
7. What color is the moon?

8. How can two objects match in one lighting and not match in another?

\section{EYES}

1. Why are eyes different colors?

2. Why does our pupil change size?

3. How are animal eyes different from human eyes?

4. Why are some people color blind?

5 . Why can't I see colors at night?

6 . Why do people get red-eye in photographs?

7. Why can't we see all the different colors (wavelengths) within one color?

8. Do you attribute the incredibly complex workings of the eye to evolution or creation?

\section{NUMBERS}

1. How many different color crayons are there?

2. What are the primary colors?

3 . Why is three an important number in color?

4. How many colors are there in the world?

5. How does a computer represent colors as numbers?

6. Can my computer really display "millions" of colors?

7. How are colors measured?

8. How many dimensions are required to describe color appearance?

\section{SEEING}

1. What's my favorite color?

2. Why do colors fade in the evening?

3. Why do flowers have different colors?

4. What does the world look like to color blind people?

5. Why can I see well outside when my mom (who's inside) thinks it's too dark to be out?

6 . What is the meaning of different colors?

7. If no light falls on an object does it still have a color?

8 . Why is color?

\section{PHOTOGRAPHY}

1. How do colors mix to make other colors?

2. What is a camera?

3. How does a color television make colors?

4. How do digital cameras detect colors?

5. Why does the moon look large on the horizon, but this doesn't show up in photographs?

6 . Why aren't my photographs the same colors as the original scenes?

7. How does an ink-jet printer produce colors?

8. Why is digital TV better than analog TV? Is HDTV really better than SDTV?

\section{CHALLENGE}

1. What is color?

2. Can different people see the same rainbow?

3. Can a dog see color as well as you?

4. If I have a room with 50 men and 50 women in it, how many will be color blind?

5 . What is the functional difference between rods and cones? 
6. What is adaptation?

7. How is color perception different from hearing?

8. What is metamerism?

An important part in <whyiscolor.org > is its last modules section entitled "Explorations", where different books and links for each one of the 6 levels is provided in order the interested reader may continue learning by him/herself.

Recently, the content of this website has been reviewed and translated into Spanish language, the final result being the book entitled "La tienda de las curiosidades sobre el color" (Mark D. Fairchild, Manuel Melgosa), published by the Editorial of the University of Granada. ${ }^{4}$ Currently this full colour book with 155 pages can be bought at the very attractive price of 20.00 Euros. Critical reviews on this book have been published in different optics journals. ${ }^{5-7}$ While the content of the website and book are almost identical, the boost for the translation of the website into Spanish language was the basic idea of the project of making science attractive and interesting to an ever wider range of readers. Note that Spanish is the third most widely-spoken language in the world after English and Mandarin, the mother tongue of approximately 426 million people in the world, and the official language in 21 countries.

\section{EXAMPLE CONTENT}

To give an idea of the materials we are suggesting here, Figure 2 gives an example of one of the modules in the book in Spanish language, the one corresponding to the question "Why do people get red-eye in photographs?" (Eyes, level 6). As you can see, as for any other question the answer is illustrated by 2 photographs with their corresponding legends, and the position of the question in the whole book is indicated by the colored square in the bottom right corner.

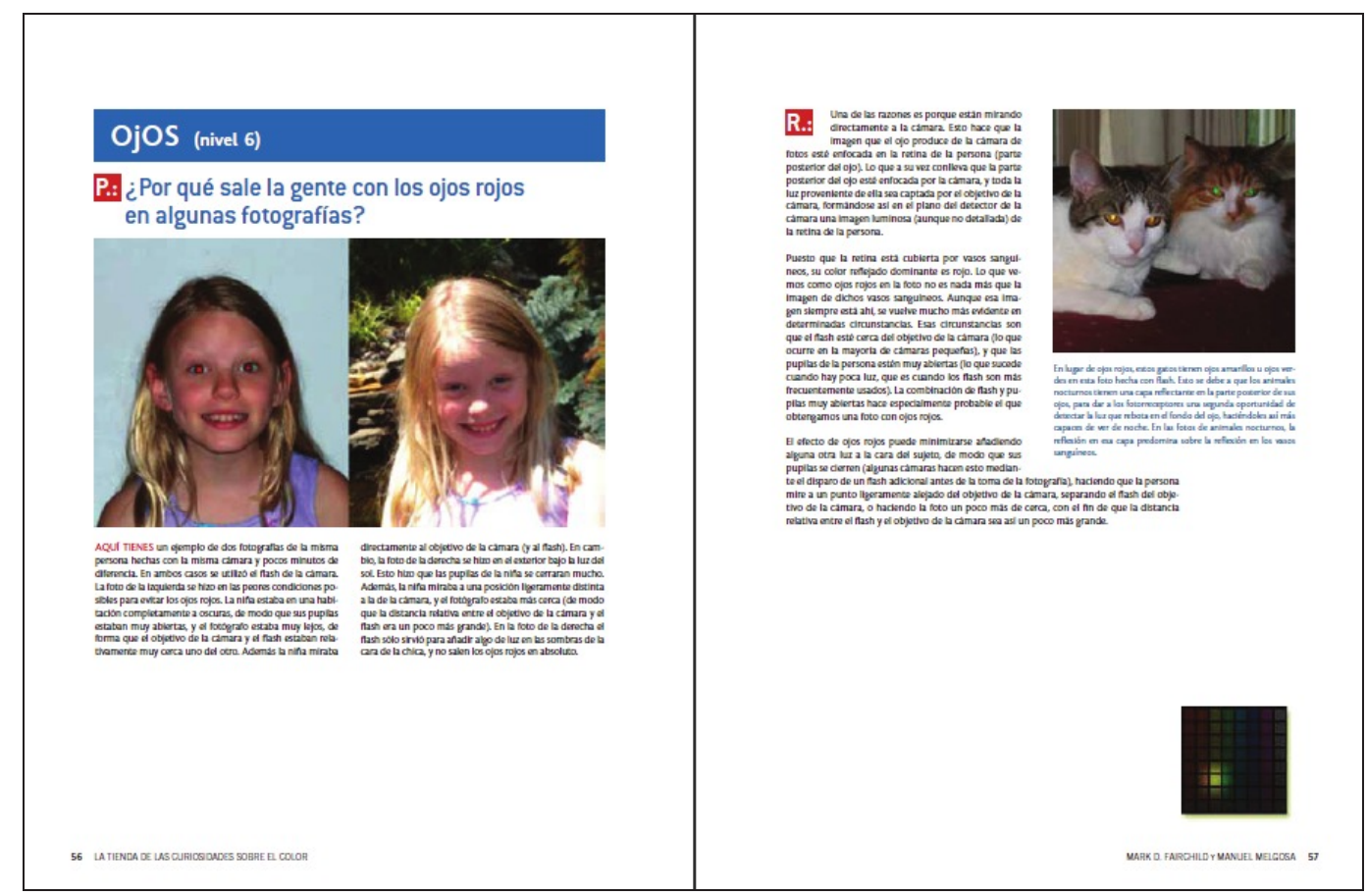

Figure 2. Example of one of the questions in the book "La tienda de las curiosidades sobre el color": "Why do people get red-eye in photographs?" (Eyes, level 6).

Text in Figure 2 is translated into English as follows:

Major Figure Legend: "Here is an example of two pictures taken of the same person with the same camera only a few minutes apart. In both cases the camera's flash was used. The image on the left was made under the worst possible conditions for red-eye. The subject was in a completely dark room so that her pupils opened wide and the 
photographer was far away so that the lens and flash were very close to each other. The subject also looked right into the camera lens (and flash). The picture on the right was done outside in sunlight. This closed down the subject's pupils. Also she looked slightly away from the camera and the photographer was closer (making the distance between flash and lens a little larger). In this case the flash only served to fill some light in the shadows on the face and there is also no red-eye at all."

Main Answer: "One reason is that they are looking at the camera! What this does is make an image of the camera in focus on the person's retina (back of the eye). That also means that the back of the eye is in focus at the camera and all the light from the back of the eyes goes right into the camera lens to make a bright (and blurred) image of the person's retina.

Since the retina is covered with blood vessels, the most dominant reflected color is red. It is the brightly reflected image of these blood vessels that we see as red-eye in the photograph. While such an image is always there, it becomes much more apparent under certain circumstances. These are when the flash is near the camera lens (which happens with most small cameras) and the person's pupils are wide open (which happens when it is dark and flashes are most commonly used). The combination of the flash and the wide open pupils makes for a particularly bright red-eye image.

The red-eye effect can be minimized by having some other light on the subject so that their pupils close down (some cameras do this with an extra flash before the photograph is taken), by having them look slightly away from the camera, by separating the flash from the camera lens, and by moving a little closer to effectively make the distance between lens and flash a bit larger."

Minor Figure Legend: "Cats get yellow-eye or green-eye instead of red-eye in flash photographs. This is because nocturnal animals have a reflective layer at the back of their eyes to give them a second chance to detect the light as it bounces back and therefore make them better able to see at night. This reflection dominates any reflection of blood vessels in photographs of nocturnal animals."

\section{A BASIC COLOUR SCIENCE BACKGROUND}

As mentioned in the materials we have introduced previously, it must be said that essentially colour is a human perception. Although colour is related to light, it cannot be stated that colour can be only understood from optics. In addition to optics, chemistry, biology, psychology, etc. play an important role in colour science. Colour is certainly multidisciplinary. But what may be an appropriate approach to start teaching colour science, for example to undergraduate students following a physics career?

Maybe a good start may be to mention some of the everyday questions we have mentioned before to emphasize that colour is in our everyday life, and physics starts from phenomenon we can see in nature. To perform some classroom demo related to colour may be also an excellent idea. Them it may be useful to emphasize that, as a first approach, we may consider that colour we perceive in most usual situations is the result of three main factors: a light source, a given object and the human visual system. This simple approach allow us to connect with important optics concepts like the spectral power distribution of light sources, the spectral reflectance (or transmittance) factor of different materials, etc. In fact these three factors (light + object + brain) are the ones included in the basic numerical colour specification currently under use: the CIE (International Commission on Illumination) tristimulus values X,Y,Z.

But students may be also aware of the complexity of the human visual system. Some appearance phenomenon, like the ones related with the influence of background on the perceived colour of a given sample, can simply illustrate that the previous three factors approach is not enough to explain what we perceive. Then, we have the opportunity to introduce the students on the field of colour appearance (with the colour-difference problem as a particular situation). They may understand the concept of "colour appearance models", ${ }^{8}$ and how these models can be used to solve practical problems related for example to colour images or colour management. Hopefully our students will be attracted because there are many exciting and unsolved problems which may be investigated.

\section{CONCLUSION}

Optics community is encouraged to make efforts to attract people to science, in particular young people with possibilities of a future career in basic scientific disciplines. We encourage optics teachers to explore the resources we have 
introduced here, make suggestions on its future improvement, to spread them to other teachers and students, if they consider it appropriate.

\section{REFERENCES}

[1] Fairchild, M. D., "Stimulating future color imaging scientists and engineers," Proc. $18^{\text {th }}$ Color Imaging Conference, IS\&T/SID, pp. 38-41 (2010).

[2] Gobierno de España. Ministerio de Educación, Cultura y Deporte. "Propuesta para la reforma y mejora de la calidad y eficiencia del sistema universitario español," Date: February 12, 2013. http://www.mecd.gob.es/prensamecd/actualidad/2013/02/20130215-comision-expertos.html

[3] National Science Foundation, Science and Engineering Indicators-2002, Arlington, Virginia (2002).

[4] Fairchild M.D., and Melgosa M., "La tienda de las curiosidades sobre el color". Editorial Universidad de Granada, 2013. ISBN: 978-84-338-5382-0.

[5] Fondazione Giorgio Ronchi, http://ronchi.isti.cnr.is. Book review from Lucia Ronchi: "About and Usa/Spain educational success: La tienda de las curiosidades sobre el color". Atti. Fond. Giorgio Ronchi LXVII (3), 2012.

[6] Óptica Pura y Aplicada, www.sedoptica.es. Book review from Francisco M. Martínez-Verdú: "La tienda de las curiosidades sobre el color". Opt. Pur. Apl. 45(3), 387-388 (2012).

[7] Color Research and Application, http://onlinelibrary.wiley.com/journal/10.1002/(ISSN)1520-6378. Book review from Rbobert C. Carter: "La tienda de las curiosidades sobre el color". Color Res. Appl. 37(6), 464-468 (2012).

[8] Fairchild, M.D. Color Appearance Models, 2nd Ed., Wiley-IS\&T, Chichester, UK (2005). ISBN 0-470-01216-1. 